\title{
El retorno a la Universidad
}

\author{
EUSEBIO FERNÁNDEZ GARCÍA
}

Los organizadores de este número extraordinario sobre el profesor Aranguren han tenido la amabilidad de solicitarme una pequeña crónica sobre su retorno a la Universidad española. Agradezco sinceramente este detalle, aunque creo que no voy a estar a la altura de las circunstancias ni de la personalidad de una figura excepcional por sus conocimientos, su magisterio y su talla humana.

Aranguren ha sido, como ha señalado Elías Diaz, uno de «los grandes maestros de la Universidad española durante, bajo y contra el régimen franquista; y también después, en la construcción de la actual democracia» ' . Pero para los que hemos tenido la suerte de conocerle, tratarle, quererle y admirarle, Aranguren ha sido mucho más: un talante, toda una forma de ser y actuar que difícilmente puede expresarse ni comprenderse bien si no se le ha conocido.

Tuve la ocasión de referirme a la trayectoria intelectual de Aranguren en el año 1993, con motivo de su investidura como Doctor honoris causa por la Universidad Carlos III, en la que oficić como padrino suyo ${ }^{2}$, y por tanto, y porque otros ya han tratado estos asuntos, me gustaría que en esta semblanza predominasen los rasgos personales sobre los académicos.

Su retorno a la Facultad de Filosofî́a de la Universidad Complutense de Madrid se produjo en octubre de 1976, tras el acto legal de la reposición en la Cátedra de Ética y Sociología, de la que había sido apartado con carácter definitivo en agosto de 1965. La expulsión de la Cátedra no significó para Aranguren la ruptura del contacto con los universitarios españoles, ni, mucho menos aún, de su integración en la realidad social y cultural española. Creo que el perjuicio mayor fue para la propia Universidad, tan necesitada de buenos profesores, y para generaciones de estudiantes universitarios que no pudieron (no pudimos) recibir sus clases.

Sin tembargo, la vuelta de Aranguren a la Universidad no creo que sea un episodio secundario, nì como dato de análisis de la transición política española a la democracia (las virtudes y defectos de su desarrollo), ni como referencia obligada en su biografía y como explicación de sus ideas e impresiones acerca de la Universidad española de esos años. Me cupo el honor de ser su ayudante durante los tres años que transcurrieron hasta su jubilación en junio de 1979 $y$, por tanto, creo que ello me convierte en un observador privilegiado de muchos acontecimientos que generalmente no son bien conocidos, unas veces

Elías Díaz, «Aranguren: la democracia como moral», en Sistema, núm. 134, septiembre de 1996, Madrid, pp. 109 y ss.

${ }^{2}$ El texto de la laudatio se publicó integramente en el Boletín mensual de la Universidad Carlos III de Madrid, núm. 9, febrero de 1993, pp. 9 y ss. 
se malinterpretan y otras no se les confiere, o no se les quiere conferir, su correcta importancia.

Con la serenidad y la objetividad que dan el paso de los años, con un no disimulado distanciamiento de la manera hipócrita de actuar de ciertas personas que prefiero no citar, pero con el preciso apasionamiento que exige la sensibilidad humana, creo que Aranguren no fue tratado como se merecía ni por parte de la Universidad Complutense ni, sobre todo, por parte de la Sección de Filosofía de su Facultad de Filosofía y Ciencias de la Educación. Deseo dejar claro que el juicio que acabo de hacer es una apreciación personal que no se funda en ningún comentario explícito del propio Aranguren (ihasta ahí llegaba su grandeza de ánimo pero también su orgullo!), pero creo que él lo pensaba así.

Para mí fueron unos años muy interesantes. Desde los últimos años del bachillerato me había gustado la lectura de los libros de Aranguren, en el Departamento de Filosofía de la Universidad Autónoma había tenido conocimiento de las clases y seminarios de Aranguren antes de su separación de la Cátedra de Ética y Sociología por parte de discípulos y alumnos suyos y en ese momento profesores míos $\mathrm{y}$, finalmente, había conocido a Aranguren en alguna conferencia y una vez que Javier Muguerza le había invitado a darnos una charla a los alumnos del Departamento de Filosofía de la Autónoma. Gracias a Gregorio Peces-Barba y a Pedro Altares pude contactar personalmente con Aranguren y proponerle mi deseo de trabajar con él en la recién devuclta Cátedra, al mismo tiempo que elaboraria la tesis doctoral bajo su dirección.

En definitiva, estaba muy ilusionado y así permanecí hasta el momento de su jubilación, pues era una extraordinaria posibilidad de aprender muchas cosas. Sus clases de las materias de Ética y Sociología y, sobre todo, los Seminarios y Cursos de doctorado estaban plagados de explicaciones y comentarios sustanciosos. También conocí a través suyo a profesores e intelectuales de relieve. Sin embargo, recuerdo especialmente «las tertulias» que teníamos antes y después de las clases, a las que también asistía José Luis Colomer. Aranguren gustaba de hacer comentarios muy agudos sobre personas y acontecimientos, tanto del pasado como de aquellos momentos tan excitantes de la transición política, primeras elecciones democráticas, Constitución, etc. Para nosotros era una experiencia insustituible, creo que él disfrutaba contándonos anécdotas y episodios y, en todo caso, su cariño, ocultado por la timidez, y un trato exquisito le hacían más llevadera nuestra ignorancia e ingenuidad. Si alguna vez tengo ganas y ánimo me gustaría escribir $y$, por tanto, recordar muchos de aquellos comentarios, algunos de ellos emitidos con cierta malicia pero siempre enjundiosos, nunca groseros y frecuentemente misericordes. El hecho de haberle acompañado en algún viaje de sus continuas conferencias por España o de haber convivido con él, durante los años siguientes, con motivo de algún Curso de Universidad de verano me permitió añadir más datos a ese conjunto de ejemplos de sabiduría práctica. 
El trato que mantenía Aranguren con los alumnos era muy afectuoso y comprensivo. No hacía nunca exámenes y recuerdo que, desde la estupidez y osadia de mi recién estrenada condición de profesor, alguna vez le critiqué su, para mí, excesiva benevolencia con los alumnos a la hora de calificar (benevolencia que aplicaba también a las tesis doctorales).

¿Y cuál era el trato con los otros catedráticos y profesores de la Sección de Filosofía? En general cortés y elegante, incluso con aquellos catedráticos que nada habían hecho para evitar su expulsión y que en algunos casos la animaron. Con tristeza pude comprobar que en el conjunto se mezclaban los que tenían mala conciencia, los irritados por el retorno de Aranguren, los miedosos y cobardes de siempre, los aprovechados y los que evitaban cualquier encuentro, como en el caso del Padre Todolí $O$. P., que sin ningún rasgo de dignidad había aceptado usurpar la Cátedra de Ética y Sociología al poco tiempo de ser expulsado Aranguren.

Evidentemente, no debe interpretarse que todos los profesores de la Sección de Filosofia puedan ser incluidos en el conjunto anterior. Sería incorrecto e injusto hacerlo así. Pero también debo decir que en la relajada isla que conformaba su despacho de pocos metros, con dos mesas, tres sillas y dos armarios de libros, me sentí muchas veces como un bicho raro. Los profesores José Hierro y José Luis Abellán hicieron lo posible para evitar un aislamiento excesivo.

Javier Muguerza ha escrito sobre estos puntos: «Su reincorporación a la cátedra fue saludada con alborozo no sólo por la comunidad filosófica del país, sino por el país en su conjunto. Pero el claustro de la Facultad de Filosofía de la ahora mal llamada Universidad Complutense, que había albergado en su seno al usurpador de la plaza de Aranguren durante aquellos años, permaneció atrincherado en su mezquindad. Sólo así se explica que Aranguren, que volvía como profesor emérito de la Universidad de California, no recibiera tal distinción al jubilarse de la suya en Madrid al cabo de tres años» ${ }^{3}$.

Pues bien, siento disentir del comentario final de Javier Muguerza. Precisamente porque conocí durante tres años la Sección de Filosofía de la Universidad Complutense pude constatar, y puedo recordar, el enorme desequilibrio entre ese alborozo del país y de la comunidad filosófica por el retorno de Aranguren a la Universidad y la realidad cotidiana de dicha Sección, mediocre intelectualmente, pobre en ética y estética, reaccionaria en lo político y con un alto grado de servilismo hacia los catedráticos perfectamente asumido por los profesores y alumnos que querian «hacer carrera». Vuelvo a insistir en que así no era todo, sino bastante. $Y$ en esas circunstancias, querido Javier, lo mejor que pudo ocurrir es que no le propusieran como profesor emérito. Además, dadas las dificultades para mantener la ilusión inicial de Aranguren,

${ }^{3}$ Javier Muguerza, «El profesor Aranguren: una visión desde la Universidad», en Retrato de José L. Aranguren, Circulo de Lectores, Madrid, 1993, pp. 60. 
quien no dejó nunca de cumplir escrupulosamente con sus tareas académicas durante esos tres años, no creo que él hubiera aceptado.

En todo caso, y ya para finalizar, fuimos muchos los que nos beneficiamos de sus dotes personales, de su profunda humanidad c ilimitados conocimicntos. Guardo un excelente recuerdo de esos tres años como profesor ayudante de Aranguren, estaría dispuesto a repetirlos y jamás desaparecerán las huellas de un cariño y respeto que germinó mucho antes, se desarrolló en esos años, se acrecentó en los siguientes y que, como lo verdaderamente importante, tiene vida eterna. 